\title{
La meritocracia en la teoría de la justicia de John Rawls
}

\section{Meritocracy in John Rawls's theory of justice}

ARTÍCULO

\author{
Matías Eckerdt \\ Universidad Nacional de Quilmes, Argentina. Contacto: matiaseckerdt@gmail.com
}

Recibido: agosto de 2020

Aceptado: octubre de 2020

\section{Resumen}

El objetivo del texto es reconstruir la tesis de John Rawls en contra de utilizar el mérito como criterio distributivo. En consecuencia, se plantea el problema de si la exclusión del mérito como criterio normativo de distribución viola (o no) alguna norma de equidad o distribución equitativa de las cargas y beneficios de la cooperación. Asimismo, la perspectiva normativa de Rawls ha suscitado objeciones en favor del mérito y de su valía como criterio distributivo, incluso en sociedades desiguales e injustas. El argumento más sólido al que refiere esta posición es que este tipo de sociedades es objetable por no reconocer algún criterio de mérito (v.g., el esfuerzo) para determinar quién/es deben obtener mayores recursos y oportunidades. A la luz de tales consideraciones, en el presente trabajo se realiza una defensa de la posición de John Rawls con relación al mérito y su invalidez como criterio distributivo, incluso en sociedades idealmente igualitarias.

Palabras claves: Igualdad de oportunidades; Meritocracia; Justicia como imparcialidad

\section{Abstract}

The goal of this text is to reconstruct John Rawls's thesis against using merit as a distributive criterion. Consequently, the problem arises as to whether its exclusion as a normative criterion of distribution violates (or not) some norm of equity or equitable distribution of the burdens and benefits of cooperation. Likewise, Rawls's normative perspective has raised objections in favor of merit and its worth as a distributive criterion, even in unequal and unjust societies. The most solid argument to which this position refers is that this type of company is objectionable because it does not recognize some criterion of merit (v.g., effort) to determine who should obtain more resources and opportunities. In light of these considerations, this paper makes a defense of John Rawls's position in relation to merit and its invalidity as a distributive criterion, even in ideally egalitarian societies.

Keywords: Equality of opportunity; Meritocracy; Justice as fairness. 


\section{Introducción}

En el presente trabajo se abordará el principio rawlsiano de la justa igualdad de oportunidades de la teoría de la justicia como imparcialidad ("justice as fairness") y su incompatibilidad con un modelo de ordenamiento social meritocrático. Para ello, se distinguirá el alcance normativo de la justa igualdad de oportunidades (o igualdad equitativa de oportunidades) y de la interpretación formal del Principio de Igualdad de Oportunidades. En la actualidad resuena con cada vez más fuerza en el sentido común el discurso del mérito individual como criterio de asignación de recursos y oportunidades, bajo el lema "cada quien debe tener lo que se merece". Según esta posición, el esfuerzo, las habilidades y talentos desarrollados por las personas en una sociedad dada deberían ser criterios de mérito válidos para determinar quién/es tendrán mayores recursos y oportunidades, justificando así las desigualdades socioeconómicas. Sin embargo, a la luz de la teoría de la justicia como imparcialidad de John Rawls, la igualdad está supeditada a tres aspectos estructurales: la operatividad de los principios de justicia en las principales instituciones políticas, sociales y económicas de una sociedad democrática determinada, la igual ciudadanía a la que sirven dichos principios y la idea de reciprocidad, propia de una sociedad justa.

\section{Contenido}

La teoría rawlsiana parte de un acuerdo público "alcanzado tras un proceso [voluntario] de debida reflexión" (Rawls, 1996, p. 6) entre las personas cooperantes, concebidas como ciudadanos libres e iguales y capaces de acordar reflexivamente unos principios de justicia que regirán en la base de la estructura social básica (constitución política, principales instituciones sociales y económicas), los cuales estarán obligados a cumplir en la sociedad en que viven durante toda su vida. La posibilidad de alcanzar tal acuerdo "se supone implícito en la cultura pública de una sociedad democrática" (1996, p. 7), por lo que nadie negaría que las personas son libres e iguales. A su vez, la cooperación estará guiada por unas reglas y principios de público conocimiento, aceptados y considerados adecuados por sus participantes. Este acuerdo implica a una pluralidad de personas que realizan elecciones voluntarias y justas en la sociedad en que viven. Por ello, la cooperación deberá darse en términos equitativos, de modo que las personas participantes que actúan conforme a las reglas y procedimientos que expresan los principios de justicia, se beneficien mutuamente. En este sentido, Rawls considera que las personas tienen dos facultades morales concatenadas con la idea de cooperación social. Por un lado, tienen un sentido de justicia, pues son capaces de restringir los beneficios individuales en aras de defender los principios de justicia consensuados con los otros. Por el otro, cada quien puede ir en busca de su 
bienestar del modo en que le apetezca, siempre y cuando ello no vaya en detrimento de los demás. En consecuencia, la persona es entendida como racional y razonable, esto es, alguien que busca medios eficaces para lograr ciertos fines (racionales), pero restringiendo estos medios y fines a su compatibilidad con cierta concepción de justicia (razonables), más precisamente, con formas de cooperación justas e imparciales, pues en la posición original las personas interesadas en alcanzar sus propios fines racionales se suponen indiferentes. En este sentido, lo racional se subsume a lo razonable, en tanto que Rawls supone la prioridad de lo justo como criterio fundamental para la convivencia por sobre la concepción de bien de cada persona. Así, la prioridad del sentido de justicia la prioridad se podría ver en el hecho de que se acepta seleccionar los principios tras un velo de ignorancia, pero el acuerdo en la elección de principios se da bajo el supuesto de que quienes están tras el velo elegirán como lo haría un sujeto racional. $Y$ es en este sentido que Rawls introduce el acuerdo en la posición original como un recurso argumentativo sólido, a partir del cual las personas, en tanto libres e iguales, elegirán cómo se repartirán los derechos y deberes de todos los ciudadanos, así como las ventajas y desventajas suscitadas de la cooperación entre los contratantes, dejando de lado los factores que nos diferencian (género, clase social, religión, intereses personales, etnia, etc.). De ello se desprende que en la posición original con el velo de ignorancia deberán garantizarse condiciones de elección imparciales, a partir de un mínimo de información disponible con respecto a las personas (libres e iguales) y la sociedad a la cual pertenecen (sistema social cooperativo), de modo que los representantes de una sociedad cooperativa puedan elegir los principios de justicia sin afección alguna de parte de las ventajas contingentes e influencias accidentales del pasado, dejándolos a todos los ciudadanos en pie de igualdad con los demás para que todos queden equitativamente situados a la hora de elegir los principios, y restringiendo la afección de las contingencias sociales y naturales al momento de elegir los principios de justicia que han de guiar nuestras acciones.

El principio de la justa igualdad oportunidades diseñado por Rawls (1995) está enmarcado dentro de los principios de justicia inicialmente aceptados en la estructura básica de una sociedad. Al primero lo denomina "igualdad de las libertades básicas"; luego, la primera parte del segundo corresponde a la "justa igualdad de oportunidades", y la segunda al "principio de la diferencia". De acuerdo con la segunda parte, las desigualdades socioeconómicas deberán satisfacer dos condiciones: (a) estar vinculadas a cargos y posiciones abiertos a todos en condiciones de igualdad equitativa de oportunidades; y (b) las desigualdades deben redundar en mayores beneficios para los miembros menos aventajados de la sociedad. Con estas consideraciones, y respetando el orden lexicográfico propuesto por Rawls, el segundo principio de justicia (justa igualdad de oportunidades) está sujeto a la prioridad del primero sobre el segundo, y tiene primacía por sobre el "principio de la diferencia". Las consecuencias fundamentales de este último aspecto atañen, por un lado, 
al hecho de que el principio de la justa igualdad de oportunidades establece límites a las desigualdades de ingreso, riquezas y otros recursos. Si bien las desigualdades socioeconómicas son permitidas, estas no deben limitar las oportunidades de los menos aventajados a manos de los mejor posicionados socialmente. Según Rawls ([1971] 2000):

Todos tienen asegurada una libertad igual para llevar a cabo el plan de vida que les agrade, en tanto no viole las exigencias de la justicia. Los hombres participan en los bienes primarios según el principio de que algunos pueden tener más si adquieren estos bienes de modo que mejore la situación de aquellos que tienen menos. Una vez que todo el sistema está establecido y funcionando, no se harán preguntas acerca de los totales de satisfacción o de perfección. Las cosas resultan de acuerdo con los principios que se elegirían en la posición original (p. 96).

Entonces sería erróneo suponer, en aras del planteamiento rawlsiano, que en una sociedad democrática cooperativa que aplica los principios de justicia acordados en la posición original, las expectativas de éxito de los individuos y las desigualdades de ingresos y riquezas deban medirse solo en función de sus esfuerzos o méritos (por cualidades individuales intrínsecas). El hecho radica en que no hay en la estructura social básica propuesta por Rawls principios que hagan mención alguna al merecimiento moral de las personas más talentosas a prosperar económicamente y detentar el domino político (Rawls, 2012). Por el contrario, las personas tienen derecho a sus dotaciones naturales iniciales, siempre y cuando respeten las reglas de reciprocidad impartidas por los principios de justicia. En consecuencia, según la referida concepción democrática de sus principios de justicia, los recursos educativos, por ejemplo, deberán ser asignados de acuerdo "al valor que tienen como medios que enriquecen la vida personal y social de los ciudadanos, incluyendo a los menos favorecidos" (Rawls, 1995, p. 107), actuando así en pos del progreso social y la dignidad y respeto que merece cada ciudadano. De este modo, garantizar una educación de calidad para todas las personas que no la recibirían por iniciativa de sus familias (v.g., por razones socioeconómicas), así también evitar grandes concentraciones de riquezas y propiedades, son acciones políticas necesarias para eliminar las barreras sociales en la competición por cargos y posiciones sociales de importancia. Pues tanto las barreras naturales, la desigualdad económica y las ventajas sociales son un condicionante de la "igualdad equitativa de oportunidades" o justa igualdad de oportunidades.

Ahora bien, ¿a qué resultados pretende arribar Rawls aplicando el principio de "justa igualdad de oportunidades"? Para ello, primero es necesario diferenciarlo de la interpretación formal del Principio de Igualdad de Oportunidades, la cual Rawls considera insuficiente cuando no es asequible a todos. Si bien una "carrera abierta a los talentos"1

\footnotetext{
1 Se utiliza este término para designar a la meritocracia como subsidiaria de la interpretación formal del Principio de la Igualdad de Oportunidades, en tanto afirma que quienes detentan el talento (credenciales educativas, por ejemplo) han de monopolizar la educación. Este término tiene su origen en las circunstancias históricas propias de la época de la Revolución Francesa, pues en ese entonces los "talentosos" estaban excluidos de las funciones públicas y de las
} 
restringe toda posible falta contra la igualdad moral de las personas (esto es, discriminaciones moralmente arbitrarias), no se consideran en dicha interpretación los factores socioeconómicos y naturales que condicionan el acceso de las personas a los recursos y oportunidades. La "carrera abierta a los talentos" exige, en cambio, la no discriminación arbitraria de los individuos al momento de acceder a un cargo público o privado, garantizándoles a todos los postulantes con la capacidad, el deseo y la voluntad de obtenerlas, el derecho legal para acceder a esas posiciones socialmente ventajosas. De este modo, se elimina la barrera de acceso impuesta por condicionantes tales como el acomodo vía "conocidos" (u otras conexiones), el género, rasgos físicos, el origen social, la orientación sexual, la etnia, etc., pues ninguno de estos factores debería ser condición necesaria para desempeñar alguna función social. Si bien en una sociedad democrática las oportunidades deberían estar abiertas para todos los ciudadanos que deseen acceder a ellas, demostrando su idoneidad para ocupar las posiciones deseadas, para Rawls los puestos o posiciones han de ser asequibles "permitiendo que todos tengan una oportunidad equitativa de obtenerlos" (Puyol, 2010, p. 136). En este sentido emerge en su teoría de la justicia como imparcialidad la igualdad equitativa de oportunidades, para compensar dichas condiciones de acceso (que resultan desfavorables para algunos). Por lo tanto, su defensa del principio de la justa igualdad de oportunidades propende a "mitigar la influencia de las contingencias sociales y de la fortuna natural sobre las porciones distributivas" (Rawls, 1995, p. 75) para mejorar la posición social de los menos favorecidos e igualar las oportunidades de acceso a los bienes sociales primarios variables, "los poderes y prerrogativas de la autoridad, el ingreso y la riqueza" (1995, p. 95). A tales efectos, la introducción del principio de diferencia exige que se diagramen instituciones sociales y políticas con el propósito de compensar las desigualdades educativas, las que sean producto del libre mercado y de las acciones gubernamentales insuficientes.

Cuando Fishkin (1983) revisa el ejemplo de los guerreros de Bernard Williams², considera que la injusticia del modelo formal de la igualdad de oportunidades radica en la omisión de las iguales oportunidades de vida, lo cual supone un error en las bases meritocráticas de toda competencia por puestos y posiciones al desarrollarse bajo condiciones muy desiguales. Consecuentemente, en un escenario tal, además de las

posiciones socialmente relevantes y lucrativas, solo reservadas a los privilegiados por haber nacido en las mejores familias. La fuerza normativa de la igualdad ante la ley posibilitó el desplazamiento del ya anticuado concepto de nación gobernada por "los privilegiados por el nacimiento", al de una en donde la igualdad ante la ley tenía más peso.

2 Bernard Williams imagina una sociedad que ha sido dominada por una clase guerrera. Sin embargo, se decide que en adelante la nueva condición de miembro de dicha clase esté determinada por la fuerza y las habilidades bélicas como valores preponderantes, y no por ser hijo de los guerreros actuales. Pero si suponemos que los hijos de las otras clases, tras extendidos períodos de dominación de los guerreros se encuentran en condiciones de salud muy malas, la selección de guerreros por tales criterios no resultaría en un ideal adecuado de igualdad de oportunidades. Las bases meritocráticas de selección se desarrollarían bajo condiciones desiguales (Fishkin, 1983, pp. 30-33). 
desigualdades socioeconómicas generacionales, los ambientes familiares propician desiguales condiciones de desarrollo de las oportunidades de vida de los niños. Sobre este aspecto, resulta interesante el aporte que hacen Wilkinson y Pickett (2009), quienes sostienen que el grado de desigualdad material que registra una sociedad ha de ser examinado a causa de las diferencias culturales y de clase que sustenta, pues "con el tiempo, las diferencias de riqueza se solapan con diferencias en la forma de vestir, en los gustos estéticos, en la educación, en la conciencia de uno mismo y en todos los demás marcadores de la identidad de clase" (2009, p. 47). En rigor, se supone que la espaciada brecha en las diferencias de renta de un país afecten a la postre su estructura de clases, pues los hijos de las familias más ricas de una sociedad $x$ seguirán sosteniendo en su educación y trayectorias de vida el ethos del sector social al que pertenecen. El corolario de esta observación es que la riqueza material y las diferencias que marcan, v.g., los estudios y la trayectoria formativa y profesional, en tanto que acumulables, definen una matriz socialmente convenida que consolida las diferencias sociales de las personas y los grupos a los que estas pertenecen. Ahora bien, ¿por qué en sociedades donde la mayoría de sus ciudadanos convienen en la importancia de igualar las oportunidades educativas, las diferencias culturales registradas entre las infancias de los entornos sociales más ricos y más pobres converge en un capital social y cultural tan dispar, que acaba afectando los rendimientos de los niños y niñas provenientes de los grupos menos favorecidos, dejándolos al margen de los beneficios inherentes a la educación de calidad brindada por el Estado? (Wilkinson y Pickett, 2009).

Una posible respuesta a dicho interrogante se encuentra en la postura teórica roemeriana, contraria a la justa igualdad de oportunidades. La posición de John Roemer (en Puyol, 2010) redefine la meritocracia invalidando el hecho de que la arbitrariedad moral de las barreras naturales (el talento y las capacidades naturales) sean las fuentes legítimas de la desigualdad, pues sostiene que "la única desigualdad moralmente aceptable entre los individuos es la derivada de la diferencia de esfuerzos: en eso consiste la nueva meritocracia" (2010, p. 133). Entonces un meritócrata bien podría argumentar que los efectos de las desigualdades en todas las esferas sociales son producto de la aplicación "ciega" del criterio de mérito, lo cual seguiría produciendo los mismos resultados, a no ser que reconozcan algún criterio de mérito (v.g., el esfuerzo) para determinar quién/es deberían obtener mayores recursos y oportunidades. A tales efectos, Roemer sostiene que es necesario distinguir entre las circunstancias que escapan a nuestro control -v.g., antecedentes familiares, genética, medio social y cultural-, pero que influyen en la capacidad de aprovechamiento y desarrollo de los recursos educativos, de los actos autónomos, de volición y esfuerzos que realizan los individuos. Bajo su punto de vista, la 
elección que hagan los individuos de un mismo tipo ${ }^{3}$ (v.g., de los sectores menos aventajados) de esforzarse, en mayor o menor medida, determinará las diferencias en su esfuerzo (producto de preferencias individuales) y legitimará la desigualdad de resultados en todas las esferas de la vida. En cambio, "la igualdad de oportunidades roemeriana no cuestiona la desigualdad de origen [...], no está comprometida con una teoría de la justicia distributiva que iguale las posibilidades de acceso a los puestos sociales de mayor importancia y prestigio" (2010, p. 131). Más bien apunta a dejar al descubierto las cuotas de responsabilidad individual, esto es, si logran (o no) convertir los recursos que les son asignados en resultados, v.g. en educación, logrando títulos para poder desplazarse del punto del espacio social donde inicialmente se encontraban los peor situados a uno mejor.

No obstante, tomando como referencia esta matriz comparativa de esfuerzos entre las personas de un mismo tipo, es interesante el aporte de Fernando Lizarraga (2019) en función del reconocimiento meritocrático y las comparaciones interpersonales e intergrupales y su afección al autorrespeto de las personas, llevándolas a algunas a percibir sus vidas como una sumatoria de fracasos. En la teoría de Rawls, este aspecto supondría una falta al más importante de los bienes primarios: el autorrespeto. El quid de la cuestión estriba, según Scanlon (en Lizarraga, 2019), en que "las ideas acerca de cuál es el nivel de recompensa económica que merecen las personas por desempeñar ciertos trabajos son, en general, una cuestión de convención social y no tienen base moral" (2019, p. 22). Dicho esto, el mérito como principio rector no es neutral en términos valorativos y culturales, por lo que su aplicación exige la democratización de los ámbitos evaluativos en los que se aplica (Young, Iris M., 2000). Ahora bien, Rawls es consciente de que el desarrollo de los talentos y la educación que cada cual recibe se ve en parte condicionada por la clase social de origen y la educación familiar. Además, en cuanto a los esfuerzos que las personas realizan, si bien son decisiones individuales, también son producto de la "Iotería" natural y social. Pero a la vez se ven cercenados estos esfuerzos por la dominación y opresión que sufren las personas de determinados grupos sociales, coadyuvando a tales efectos los patrones culturales normativos que rigen en el corazón de toda institución social. Cabe mencionar en este punto lo referido por Olof Page (2008) respecto del rechazo de Rawls al mérito como principio distributivo preinstitucional, esto es, a no merecer "nada de aquello en virtud de lo cual podemos obtener los beneficios que nos hacen estar mejor que otros" (p. 41). En $A$ Theory of Justice, sostiene, se afirma que el carácter está determinado por algunas contingencias sociales y naturales, por lo que también el esfuerzo está a su merced, de modo que "si el esfuerzo es en parte el resultado de una cadena casual (compuesta por

\footnotetext{
3 Según Roemer (1998), la medición de esfuerzos individuales se ejecuta con relación a los integrantes de un mismo tipo de persona, lo cual constituye un aspecto normativo fundamental de su propuesta teórica, pues la comparación se hará entre todas aquellas personas que se encuentren en el mismo percentil de ingresos, siendo la posición de cada cual del mismo tipo resultado de las elecciones de esfuerzos a realizar.
} 
circunstancias naturales y sociales) es posible sostener que también lo son las preferencias" (2008, p. 43). Esto nos conduce a pensar en la responsabilidad de las personas por su tendencia (o no) a esforzarse, considerando la formación del carácter como resultado de variables sobre las que no tenemos control, y que inhabilitarían al esfuerzo como un criterio de mérito moralmente legítimo. Pero si reconocemos que a la vez somos responsables de nuestras elecciones, objeta Page, en tanto poseedores de cierta capacidad para regular nuestras preferencias y asumir la responsabilidad de nuestros actos, "Rawls debería corregir sus afirmaciones [...] respecto de los efectos de la lotería natural ya que en dichas afirmaciones se sostiene que no merecemos, por ejemplo, nuestro carácter porque nos ha sido dado y porque no tenemos mayor control sobre él" (2008, p. 51). Probablemente no podamos sortear la arbitrariedad de la naturaleza, pero sí compensarla redistribuyendo recursos o medios, que es el tipo de justicia que ofrece Rawls para que las personas peor situadas puedan mejorar su calidad de vida y tender a la consecución de los proyectos de vida más afines a sus preferencias, toda vez que las bases del autorrespeto como un principio sólido funcionan en su teoría como rectoras de las dominaciones y opresiones que socavan la libertad de los individuos en las sociedades democráticas constitucionales.

Además, a la luz de la objeción de Page, ¿un diseño social basado en el mérito y no en contingencias moralmente arbitrarias, acapararía un procedimiento "justo" de selección solo haciendo foco en las calificaciones, las habilidades, los talentos y el esfuerzo, pero obviando la dominación y opresión institucional que socava las libertades de personas pertenecientes a ciertos grupos sociales? En principio, podríamos estar de acuerdo con una justicia procedimental de este tipo, pues como ejemplifica Roemer, “¿debiera concederse el título de cirujano a aquellos individuos que suspendan los correspondientes cursos, si se hubiesen esforzado mucho y proviniesen de entornos desfavorecidos?", ante lo cual responde que a todos los aspirantes debería corresponderles la aplicación de una política de igualdad de oportunidades durante "el proceso de admisión en las facultades de Medicina. Pero convertirse en un cirujano requiere competir después por tal puesto: aplicaría el principio de no discriminación a la concesión del título o a la contratación de cirujanos" (1998, p. 84). De este modo, aquellas personas menos favorecidas, quienes "pese a su esfuerzo, no superasen los cursos correspondientes no obtendrían su título, de aplicarse esta regla, ni tampoco ningún hospital se vería en la obligación de contratarlos" (1998, p. 84). Sin embargo, y atendiendo a las objeciones de la izquierda a este planteo, la sociedad está en deuda con las personas de los sectores menos favorecidos, exigiendo compensar las circunstancias "contingentes" de las que la sociedad no se hace responsable. Este argumento intenta justificar que se les conceda el título a los menos favorecidos, aunque se viera reducida la calidad de las intervenciones quirúrgicas, ya que la sola presencia de individuos de estos tipos en esta profesión alentaría a muchos otros de su tipo a prepararse para estudiar medicina. Sin embargo, Roemer (1998) desacredita esta posición, pues 
sostiene que "el coste social de cubrir unos puestos con individuos relativamente incompetentes sería mayor que el beneficio que se obtendría con ello", y agrega, "los beneficios que reciben de la educación los individuos desfavorecidos y lo que con ello obtiene la sociedad son mayores que el coste social inmediato de las oportunidades perdidas por aplicar en tales casos una política de igualdad de oportunidades" (p. 86).

Como contrapartida del planteo roemeriano, el riesgo continúa siendo que el mérito alcanzado por las cuotas de esfuerzos diferenciales invertidos por las personas en cada tipo siga dejando en evidencia la desigualdad de posesión de bienes sociales primarios, perpetrando en sus posiciones a quienes se esfuerzan y obtienen los resultados con los recursos disponibles, y obturando las oportunidades de los menos aventajados. Si optáramos por aplicar la propuesta roemeriana, ¿podríamos asegurar que se aplicaría a todas las personas un mismo valor de la libertad? Y en la teoría de la justicia de Rawls, ¿los menos aventajados deberían aceptar las desigualdades existentes (satisfaciéndose el principio de diferencia) para mejorar su capacidad de alcanzar sus fines, siendo que si no fuera así, su capacidad sería menor y desembocaríamos en un esquema de libertades desiguales en la estructura social básica?, ¿en este marco de derechos, quedaría justificado el diferencial de esfuerzos roemeriano? Desde luego, cabe preguntarnos si realmente la igual libertad compartida por todos los ciudadanos en la estructura básica de toda sociedad democrática es condición suficiente para alcanzar los fines de la justicia social anclando sus preceptos en la distribución de los bienes sociales primarios (ingresos, riqueza, oportunidades, libertades, bases sociales de la autoestima), y a través de una distribución de recursos y medios (v.g., mejoras salariales, reducción impositiva, programas sociales). $\mathrm{Si}$ el resultado de nuestras acciones fue producto de nuestras acciones y elecciones personales, ¿son todas estas consecuencias "justas" y "merecidas" condición suficiente para desatender la desigualdad de oportunidades que sufren los individuos (producto de la opresión y dominación que unos grupos ejercen sobre otros)? En el caso de la movilidad social, los hijos de las familias más ricas y socialmente prestigiosas, o de clase media y media alta, cuyas familias se preocupan por que tengan mejores oportunidades sociales, ¿ellos merecen este camino más allanado, a pesar de que la herencia social atente en favor de la desigualdad de clase, género, cultural y étnica? En todo caso, es necesario atender a las desigualdades de oportunidades estructurales de efecto acumulativo, que cada vez más desnivelan el terreno de juego en favor de los hijos de familias cuyo origen social les depara un destino mejor que a otros, quienes, en última instancia, conseguirán sortear los obstáculos y progresar con esfuerzos y algo de suerte. Aunque esto no debe recaer en responsabilidades individuales ni producto de la herencia genética.

Si bien es posible que el principio de la diferencia propuesto por Rawls mitigue al interior de las instituciones educativas las desventajas que padecen los individuos peor posicionados socialmente, es la estructura social la causa de la injusticia educativa y no 
viceversa (Rawls, 1995; Satz, 2007; Dubet, 2011). En última instancia, si los talentos naturales facilitan el goce de oportunidades diferenciales de vida para unos pocos, es porque socialmente se valora, reconoce y premia a estas personas por lo que pueden aportarle a la sociedad. Contribuyendo a tales efectos, Wilkinson y Pickett (2009) afirman, tras una serie de experimentos científicamente probados, que "en la tarea educativa, los resultados y el comportamiento pueden verse profundamente afectados por como sentimos que nos ven y nos juzgan los demás. Cuando esperamos que nos consideren inferiores, nuestras capacidades parecen disminuir" (2009, pp. 135-136). En este sentido, se reconocen tales "sesgos" y prejuicios, al igual que Iris M. Young, como acciones que forman parte de una red de "discriminación" que refuerza la opresión, por lo que deben ser intervenidas con otras formas de "discriminación" (políticas de acción afirmativa), que ayuden a socavar la opresión que padecen ciertos grupos (a través de prácticas preferenciales conscientes de otros grupos). Por ello, es imprescindible que al interior de las sociedades se le preste especial atención a "los efectos moralmente injustificados de la desigualdad de oportunidades estructural" (Puyol, 2010, p. 213), a las causas de la injusticia social, a las desigualdades existentes dentro del grupo de los menos aventajados (pues allí también sus miembros padecen situaciones de dominación y opresión, sea por el género, la raza, la etnia o grupo cultural de pertenencia, entre otras tantas, que combinadas con su posición en el espacio social resultan explosivas). A pesar de que las teorías de la justicia están más bien preocupadas por las desigualdades antes que por regular los sistemas de creencias que forman parte de la estructura social básica, Rawls es consciente de que "los efectos de la estructura básica de la sociedad son muy profundos y penetrantes, estando presentes desde su nacimiento. Esta estructura favorece algunas posiciones iniciales frente a otras en la división de los beneficios de la operación social" (Rawls, 1995, p. 97). En consecuencia, la interpretación formal del Principio de Igualdad de Oportunidades, en tanto se mantengan las desigualdades estructurales, seguirá siendo insuficiente; o bien, una ficción o mito (Dubet, 2011), pues su basamento en el principio del mérito no crea situaciones verdaderamente "justas", más bien justifica las injusticias sociales a partir de lo que los individuos con los méritos suficientes (esfuerzos invertidos más capacidades adquiridas) deberán merecer. Así, solo los talentosos aprovecharán las oportunidades de movilidad social, y contribuirán a profundizar aún más las desigualdades socioeconómicas de la sociedad en cuestión. ¿Pero qué sucede entonces con quienes no tienen ni han realizado los méritos necesarios? ¿Estarán destinados a ser ayudados por los "más talentosos"? ¿O tendrán ellos posibilidad alguna de estar "del otro lado"? La interpretación formal del Principio de Igualdad de Oportunidades se ampara en los "milagros": jóvenes nacidos en familias pobres, pero con un talento innato y cuotas de grandes esfuerzos que los ha llevado a posiciones sociales ventajosas y a obtener una mejora con respecto a su posición social de origen, o bien los golpes de suerte típicos del sueño americano (con esfuerzo, y algo de suerte, todo se logra). 
Sin embargo, la existencia de milagros y American dreams no mejora estructuralmente la posición social de los menos aventajados, ni sus condiciones de vida.

Ahora bien, considerando la esfera de la familia como una de las ventajas/desventajas para la movilidad social, para los defensores de una equidad fuerte (Fishkin, 1983, pp. 2021), como lo es Rawls, la intromisión del Estado en ella resultaría una acepción aún más severa que el mérito individual como criterio de igualación de las oportunidades. Ningún teórico liberal igualitarista podría estar de acuerdo con limitarle a las familias el tipo de educación que decidan para sus hijos, lo cual no justifica las desigualdades producto de la herencia social, pero sí el derecho a respetar su autonomía. Así, en caso de que se viole dicha autonomía, sí cabría utilizar el criterio de mérito, pues "las personas merecen lo que las expectativas legítimas determinan [...] porque así lo han establecido previamente los principios de justicia" (Olof Page, 2008, p. 39). En este sentido, el mérito es aplicado como una categoría institucional antes que preinstitucional, toda vez que no sustenta sus argumentos apelando a la idea de mérito moral, lo cual "supondría la existencia de un criterio independiente de los principios mismos" (2008, p. 40), amarrando así la validez de los principios de justicia al mérito moral y no al acuerdo en una "situación de igualdad".

Consecuentemente con el planteo rawlsiano, Debra Satz (2007) sostiene que una igualación vertical de oportunidades es compatible con la idea democrática de que "todos los individuos tienen derecho a los mismos derechos y libertades independientemente de su origen social” (2007, p. 631). Y agrega que las causas de la desigualdad son un elemento a tener en cuenta, si aceptamos el principio de una justa igualdad de oportunidades, ya que mientras se siga permitiendo que haya familias que no tengan acceso a ciertos bienes y servicios (a un empleo digno, al sistema de salud, a la capacitación laboral, al apoyo familiar, etc.), la educación impartida en las instituciones escolares será insuficiente para asegurar el desarrollo equitativo del potencial de los niños. Y agrega, que "los resultados educativos desiguales están más fuertemente influenciados por factores exógenos que por la financiación escolar y las propias escuelas" (2007, p. 633). Asimismo, comparte con Roemer el hecho de que la aplicación diferencial de esfuerzos no podría ser compensada por completo con una política de igualdad de oportunidades. Pero, enfatiza Satz, suponiendo que las capacidades diferenciales del grupo de los menos aventajados (o los tipos, según el planteo de Roemer) sí están influenciados por las circunstancias, además del esfuerzo que cada uno de los individuos pertenecientes a ese sector aplica para transformar los recursos disponibles en logros educativos, cabe la implementación de políticas de igualdad de oportunidades que compensen a las personas con cantidades diferentes de recursos. Aunque una distribución diferencial de recursos educativos, sostiene Satz, seguiría perpetrando la creación del mérito y determinando quiénes ocuparán los primeros lugares al momento de postularse a los empleos o al ingreso a las mejores universidades, incurriendo también en una posible falta al autorrespeto de las personas como producto de 
la diferenciación de esfuerzos e inversiones distritales en recursos educativos. De este modo, en el marco de la teoría rawlsiana, no es lícito detener la influencia excesiva de los padres en la formación, motivación y desarrollo del talento de sus hijos. Pero si esto conduce a las sociedades a enormes desigualdades generacionales susceptibles de sostenerse en el tiempo, ¿cómo es posible salvar este contrapunto?

Si bien Rawls acepta la idea intuitiva de que los individuos tengan porciones desiguales de bienes sociales, resultado de la cooperación social, al mismo tiempo advierte la influencia de las contingencias naturales y sociales (moralmente arbitrarias) -la clase social y la dotación inicial de talentos individuales- en la distribución de los individuos a las posiciones socialmente ventajosas. Para evitar que la "lotería" natural y social devenga en grandes injusticias y afecte los proyectos de vida de los individuos, Rawls apela al principio de diferencia para mitigar los defectos fortuitos antes mencionados. Asimismo, sostiene que la adquisición de conocimientos, habilidades y técnicas culturalmente valiosas no deberían depender de la posición de clase ni de los talentos naturales. Para ello se vale de dos exigencias institucionales necesarias para garantizar la justa igualdad de oportunidades. Por un lado, impedir la acumulación excesiva de propiedades y riqueza; por el otro, mantener la igualdad de oportunidades educativas para todos. De este modo, deja en evidencia el valor democrático que ha de tener la educación como bien social facilitador para el acceso a los mejores empleos y profesiones, pues presupone que "aquellos que se hallan en el mismo nivel de talento y capacidad, y que están igualmente dispuestos a hacer uso de ellos, deben tener las mismas perspectivas de éxito, independientemente del lugar inicial que ocupan en el sistema social” (Rawls, 1995, p. 79). La distribución justa propuesta por Rawls inclina su eje hacia el prioritarismo, esto es, enfocando "la atención sobre la distancia social entre aquellos que tienen menos y el ciudadano medio" (1995, p. 99), y dándole prevalencia a los menos aventajados en orden del reparto de recursos educacionales (Satz, 2007). Aunque la igualación de las oportunidades educativas no necesariamente reflejará una reducción de las desigualdades socioeconómicas. De aquí que Rawls haya hecho hincapié en aplicar el principio de diferencia en acciones tendientes a mejorar ciertos bienes sociales primarios (v.g., los ingresos) que una vez aplicado el principio de la justa igualdad de oportunidades no pudieron ser compensados. De este modo, los individuos talentosos, arbitrariamente distribuidos, cooperarían socialmente bajo la figura de un "acervo común", de modo tal que los beneficios de los más afortunados por la lotería social y natural sean ventajosos para quienes tienen menos dotes naturales y/o hayan nacido en posiciones las sociales más desfavorecidas.

Situados del lado de una sociedad cuya estructura básica tienda a asegurar el principio de la justa igualdad de oportunidades, "el precepto de: a cada quien según su contribución, en la forma particular de a cada quien según sus conocimientos o su educación" no tendría demasiado valor, pues en una sociedad que se vale del principio mencionado habrá "muchas 
más personas recibiendo los beneficios de la enseñanza y la educación", incrementándose "la oferta de personas capacitadas" (Rawls, 1995, p. 280). Esto quiere decir que el conjunto de las instituciones sociales deberá garantizar la "igualdad de oportunidades para la educación y la cultura de personas similarmente capacitadas, y [mantener] los trabajos y los empleos abiertos a todos, sobre la base de las capacidades y de los esfuerzos razonablemente relacionados con las tareas y trabajos pertinentes" (1995, p. 257). De este modo, apelando al principio de diferencia, la brecha entre los ingresos de quienes perciben la renta más baja y la más alta tenderá a ser cada vez más estrecha, pues a las personas les parecerá lícito aceptar, en la posición original y tras un velo de ignorancia, que los talentos naturales desigualmente distribuidos formen parte de los bienes sociales comunes, pues quienes detenten los beneficios de dicha distribución deberán actuar en favor de quienes hayan resultado con peor suerte en la "lotería" natural. En este marco de derechos rawlsiano, el objetivo del principio de diferencia (en conjunto con los principios de las libertades básicas y la justa igualdad de oportunidades) estriba en tender a que las personas sean atraídas a "posiciones en las que son más necesarias desde un punto de vista social, alentarles a aceptar el peso de las responsabilidades particulares, y hacer todo eso de modo consistente con la libre elección de ocupación y la igualdad equitativa de oportunidades" (Rawls, 2012, p. 114). Desde la perspectiva de Olof Page, "el rechazo de Rawls del mérito como principio preinstitucional hace pensar que son los principios de justicia escogidos en la posición original los que, al distribuir derechos y deberes, asignan responsabilidad a los individuos por sus preferencias" (Olof Page, 2018, p. 45). De nuevo, si bien "el esfuerzo que una persona está dispuesta a hacer es influido por sus capacidades naturales, sus conocimientos, y las alternativas que se le ofrecen" (Rawls, 1995, p. 284), no hay ningún precepto de la justicia en la teoría rawlsiana que aspire a una virtud recompensadora, pues las "recompensas obtenidas por escasos talentos naturales, por ejemplo, han de cubrir los costos de enseñanzas y alentar los esfuerzos del aprendizaje, además de dirigir las distintas capacidades hacia donde mejor se favorezca el interés común" (Rawls, 1995, p. 284). En efecto, a pesar de la responsabilidad por delegación, tal y como sostiene Lizarraga (2019), Rawls está lejos "de promover la esclavitud de los talentosos, ya que a los más afortunados se les permite obtener ventajas para cubrir los costos de su entrenamiento y educación" (2019, p. 12). En este sentido, no es lícito afirmar que los más aventajados tengan "derecho a un esquema cooperativo que les permita obtener aún más beneficios en formas que no contribuyan al beneficio de los demás, ya que no merecemos nuestro lugar en la distribución inicial" (2019, p. 13). Sin embargo, según las observaciones de Olof Page a los argumentos de rechazo al mérito moral por parte de Rawls, "resulta difícil imaginar qué espacio le queda (si es que le queda alguno) a la responsabilidad que el propio Rawls le atribuye a las personas" (Olof Page, 2018, p. 42), ya que no merecemos nuestro carácter por ser dependiente de las contingencias sociales y naturales (moralmente arbitrarias). Su postura 
se sitúa en que si "las personas tienen la capacidad de ajustar y revisar sus fines", siendo parcialmente responsables de su formación y del cultivo de sus fines y preferencias, "no es injusto 'hacer a las personas responsables de sus preferencias y exigirles que se las arreglen como mejor puedan'” (Rawls, 1982), pues "las personas son personas morales, tienen la capacidad de ajustar y revisar sus fines y ser, en consecuencia, responsables de ellos. Negar su responsabilidad por los fines implica negar su condición de personas morales" (2018, p. 43). Situado sobre estos argumentos, Olof Page se indaga acerca de "por qué si tenemos algún papel en la formación y cultivo de nuestras preferencias -y somos, por tanto, parcialmente responsables de ellas- el esfuerzo que realizamos no merece ningún tipo de reconocimiento" (2018, p. 44). En respuesta a su objeción, si bien Rawls admite que el carácter que nos posibilita hacer el esfuerzo para desarrollar nuestras habilidades y talentos depende, en gran medida, de las condiciones sociales y familiares durante la niñez -algo de lo que nadie debería atribuirse como meritorio-, a la vez que le confiere a los ciudadanos algún papel en la formación y cultivo de sus fines y preferencias, también deja entrever el mayor y menor peso que tienen tales condicionantes. Efectivamente, una cuota de bienes primarios que satisfagan las necesidades de las personas no necesariamente les permitirán "arreglárselas bien respecto de su plan de vida" (2018, p. 50), lo cual establece ciertos límites a la responsabilidad individual, además de las desigualdades e injusticias estructurales a las que aluden Iris M. Young y F. Dubet. Entonces, si bien cabe en la justicia como imparcialidad rawlsiana la posibilidad de responsabilizarnos de nuestras decisiones, la metafísica volitiva no debería fundamentar las desigualdades socioeconómicas; en efecto, el marco de derechos que establece Rawls en su teoría de la justicia como imparcialidad convierte los "reclamos de sentido común en expectativas legítimas que todas las personas aceptarían en la hipotética posición original" (Lizarraga, 2019, p. 13), de modo que "los derechos básicos no se pueden romper con las decisiones voluntarias que toman los individuos [...] [ni] la desigualdad de resultados que se deriva del ejercicio de la responsabilidad individual puede afectar a los derechos básicos" (Puyol, 2010, p. 215). De este modo, en la teoría de la justicia rawlsiana las personas aceptarían las "desigualdades en el ingreso y la riqueza, y diferencias en autoridad y grado de responsabilidad" distribuidas en todas las esferas de la sociedad, pues estas "operan para mejorar a cada un[a] en comparación con el punto de partida de la igualdad" (Rawls, 2002, p. 178), una vez garantizadas sus libertades básicas y la justa igualdad de oportunidades. Atendiendo a lo expuesto, ¿por qué no permitiríamos un esquema cooperativo tal en nuestras democracias constitucionales? 


\section{Referencias bibliográficas}

Dubet, F. (2011). Repensar la justicia social. Contra el mito de igualdad de oportunidades. Buenos Aires: Siglo XXI.

Fishkin, J. (1983). Justice, Equal Opportunity, and the Family. New Haven: Yale University Press.

Lizárraga, F. (2019). Igualitarismo y meritocracia: de Rawls a Scanlon. Páginas de Filosofía, 23, 7-32.

Page, O. (2008). Mérito y responsabilidad: Rawls y la igualdad democrática. Revista de Ciencia Política 28(2), 33-52.

Rawls, J. (1995). Teoría de la justicia. México D.F.: Fondo de Cultura Económica.

Rawls, J. (1996). La justicia como equidad: política, no metafísica. En La Política, 1, 23-46.

Rawls, J. (2002). La justicia como equidad. Una reformulación. Barcelona: Paidós.

Roemer, J. (1998). Igualdad de oportunidades. Isegoría, O(18), 71-87.

Sandel, M. (2013). Lo que el dinero no puede comprar. Buenos Aires: Debate.

Satz, D. (2008). Equality, Adequacy, and Educational Policy. Education Finance and Policy, 3(4), 424-443.

Young, I. M. (2000). La justicia y la política de la diferencia. Madrid: Cátedra.

Wilkinson, R. y Pickett, K. (2009). Desigualdad. Un análisis de la (in)felicidad colectiva. Madrid: Turner Noema. 